\title{
SKYPE: FERRAMENTA PEDAGÓGICA USADA COMO APRENDIZAGEM COLABORATIVA NOS ESTÁGIOS SUPERVISIONADOS
}

\author{
MARINGÁ/PR JULHO/2018
}

\author{
Antoneli da Silva Ramos - UNICESUMAR - antoneli.ramos@unicesumar.edu.br \\ Priscilla Campiolo Manesco Paixão - UNICESUMAR - priscilla.paixao@unicesumar.edu.br \\ Rebecca Manesco Paixão - UNICESUMAR - rebeccapaixao@gmail.com
}

Tipo: Relato de Experiência Inovadora (EI)

Categoria: Métodos e Tecnologias

Setor Educacional: EDUCAÇÃO SUPERIOR

\begin{abstract}
RESUMO
A dicotomia entre teoria e prática nas disciplinas de Estágio Supervisionado sempre foi tratada como um grande problema durante a concepção dos cursos de Licenciaturas das Instituições de Ensino Superior. Na IES em estudo, a reflexão sobre a práxis docente constante e o diálogo entre os acadêmicos dos mais distintos cantos do Brasil e professores vinculados aos cursos foram princípios críticos e transformadores desta realidade. No presente estudo foi proposta a utilização do Skype como ferramenta pedagógica capaz de transformar a realidade experienciada dos alunos durante a realização dos estágios supervisionados por meio de uma aprendizagem colaborativa. Os resultados foram positivos e demonstraram o aumento da audiência e participação dos alunos, cuja média anual de 22,5\% passou para 61,5\%, no período compreendido entre os anos de 2016 e 2017.
\end{abstract}

Palavras-chave: Estágio Supervisionado; Aprendizagem Colaborativa; Skype. 


\section{INTRODUÇÃO}

O Estágio Curricular Supervisionado é prática obrigatória nos cursos de Licenciatura conforme preconiza as Diretrizes Curriculares Nacionais para a Formação Inicial e Continuada dos Profissionais do Magistério da Educação Básica. Na UNICESUMAR Centro Universitário de Maringá, os estágios supervisionados dos cursos na modalidade a distância atendem à legislação vigente, possibilitando aos acadêmicos reflexões acerca do trabalho docente, correlacionando a fundamentação teórica obtida nas demais disciplinas da matriz curricular do curso com as observações investigativas realizadas.

Defendendo-se a unicidade entre a teoria e a prática nos estágios supervisionados, acredita-se que o uso de ferramentas pedagógicas utilizadas como facilitadoras do processo de ensino e aprendizagem na Educação a Distância pode favorecer uma formação docente mais sólida e repleta de trocas de experiências entre acadêmicos/acadêmicos e acadêmicos/professores, na busca pelo aprimoramento profissional.

Assim, esta pesquisa traz em seu bojo a análise de dados quanti/qualitativos no período compreendido entre 2016 e 2017 referentes à mudança de concepção e metodologia nos estágios, utilizando-se de uma aprendizagem colaborativa.

Partindo deste pressuposto, apresentamos a importância dos Estágios Supervisionados nos cursos de Licenciaturas, a discussão acerca da aprendizagem colaborativa e a análise dos dados que comprovam a eficácia do uso de Skype como ferramenta pedagógica capaz de desenvolver a aprendizagem colaborativa.

\section{IMPORTÂNCIA DO ESTÁGIO SUPERVISIONADO E A APRENDIZAGEM COLABORATIVA}

O estágio curricular supervisionado nos cursos de Licenciaturas configura-se como um espaço de reflexão da ação docente, sistemático e permanente, que contextualiza as formas de transmissão, reprodução e produção do conhecimento. Um espaço investigativo, dinâmico e também articulador das diversas disciplinas que compõem as matrizes curriculares promovendo a formação da identidade profissional, de sujeitos sociais e do debate e a construção de pensamentos pessoais críticos.

Atendendo a Resolução CNE/CP 2 de $1^{\circ}$ de julho de 2015, o componente Estágio 
Curricular Supervisionado é desenvolvido a partir de uma concepção teórico-prático, com carga horária total de 400 horas/aula. Segundo tal resolução, são:

II - 400 (quatrocentas) horas dedicadas ao estágio supervisionado, na área de formação e atuação na educação básica, contemplando também outras áreas específicas, se for o caso, conforme o projeto de curso da instituição (BRASIL, 2015, p. 11).

Mas, por que o estágio provoca tantas dúvidas e insegurança por parte dos acadêmicos? Será pouca familiaridade com o ambiente escolar, falta de prática pedagógica e contato insuficiente com as diversas formas de conceber a educação? Muitas pessoas argumentam que o estágio é uma "prática" que se utiliza de uma "teoria", diferente daquela que se aprende no curso. Estas indagações provocaram inquietações que nos fizeram repensar o estágio.

Partiu-se, então, da ideia de que o estágio curricular supervisionado deve realizar-se em "situação real", dando oportunidade para que o acadêmico se defronte com o contexto escolar, sua dinâmica própria e as realidades concretas do processo ensino e aprendizagem, mesmo em se tratando de cursos de licenciaturas ofertados na modalidade a distância.

Essa atitude investigativa envolve análise, reflexão e intervenção na vida da escola, dos professores, dos alunos e da sociedade. Segundo Passerini (2007, p. 32 apud JANUÁRIO, 2008, p. 1),

\footnotetext{
o Estágio Supervisionado é o primeiro contato que o aluno-professor tem com seu futuro campo de atuação. Por meio da observação, da participação e da regência, o licenciando poderá refletir sobre e vislumbrar futuras ações pedagógicas. Assim, sua formação tornar-se-á mais significativa quando essas experiências forem socializadas em sua sala de aula com seus colegas, produzindo discussão, possibilitando uma reflexão crítica, construindo a sua identidade e lançando, dessa forma, "um novo olhar sobre o ensino, a aprendizagem [e] a função do educador".
}

Infelizmente por muito tempo o estágio reduziu-se a observar os professores em aula, elaborar e executar "aulas modelos", sem proceder a uma análise crítica fundamentada teoricamente e legitimada na realidade social em que o ensino se processa (PIMENTA, 2009).

Não nos contentamos com essa imitação de modelos. Assim, enquanto professores universitários, precisamos encontrar mecanismos que possibilitem aos acadêmicos estagiários o contato com seu futuro campo de atuação e é lá que terão contato com os alunos, com a realidade da sala de aula, com o sistema educacional e, ainda, com seus futuros colegas de profissão, em quem, algumas vezes, tomarão como referências, boas 
ou não, para a sua prática pedagógica (JANUARIO, 2008, p.1).

O licenciando precisa desenvolver sua prática pedagógica associada à teoria, e desenvolver técnicas conforme as diversas e diferentes situações em que o ensino ocorre. Para que isso aconteça Piconez (2004), afirma que o espaço do estágio é o eixo que pode articular esta interação teoria-prática entre os conteúdos.

Segundo Barreiro e Gebran (2006, p. 22),

A articulação da relação teoria e prática é um processo definidor da qualidade da formação inicial e continuada do professor, como sujeito autônomo na construção de sua profissionalização docente, porque lhe permite uma permanente investigação e a busca de respostas aos fenômenos e às contradições vivenciadas.

Desse modo, o estágio precisa estar vinculado à prática de ensino, através de uma dimensão ideal, teórica, subjetiva, articulada com diferentes posturas educacionais, e uma dimensão real, material social e prática, própria do contexto da escola brasileira (PICONEZ, 2004, p.25).

O Estágio Supervisionado deve ser organizado e planejado de modo coerente com os objetivos que se pretende atingir, proporcionando a imersão do futuro professor no contexto profissional.

Em se tratando de licenciaturas ofertadas na modalidade a distância optamos por trabalhar com a aprendizagem colaborativa.

A aprendizagem colaborativa foi construída sobre as bases do construtivismo (Piaget) e das teorias socioculturais (Vygotsky) e com o avanço cada vez maior das tecnologias da informação e da comunicação, se tornou uma metodologia apropriada para as disciplinas de Estágio Supervisionado.

A aprendizagem colaborativa é "uma proposta pedagógica na qual estudantes ajudamse no processo de aprendizagem, atuando como parceiros entre si e com o professor, com o objetivo de adquirir conhecimento sobre um dado objeto" (CAMPOS et al., 2003, p. 26).

Nestas disciplinas de Estágio Supervisionado dos cursos de licenciaturas a aprendizagem colaborativa permite aos acadêmicos mudarem suas posturas, de um estudante solitário para um que colabora com a aprendizagem do grupo, trocando ideias e se fortalecendo enquanto futuros profissionais da educação. Isto porque, "quando os alunos trabalham em conjunto, isto é, colaborativamente, produzem um conhecimento 
mais profundo e, ao mesmo tempo, deixam de ser independentes para se tornarem interdependentes" (PALLOF e PRATT, 2002, p. 141).

Nestes moldes a aprendizagem colaborativa reúne os alunos matriculados nos estágios supervisionados em torno de um só objetivo: discutir a prática docente através das experiências concretizadas durante os estágios correlacionando a teoria aprendida à prática vivenciada. Isto permite a consolidação de novos conhecimentos.

\section{METODOLOGIA}

A partir dos apontamentos, foi realizada uma pesquisa com os alunos matriculados nas disciplinas de Estágio Supervisionado na instituição de ensino UNICESUMAR - Centro Universitário de Maringá, dos cursos de Licenciaturas EAD em Matemática, História e Geografia, a partir da mudança da metodologia empregada nos seminários, por meio da utilização do Skype.

Para o levantamento dos dados, foram utilizados como indicadores aqueles registrados na base institucional, a qual apresenta todos os registros dos acadêmicos, desde o acesso a plataforma de aprendizagem até o registro de atividades realizadas, audiência nas aulas, download do material didático entre outros.

\section{RESULTADOS E DISCUSSÕES}

Como os estágios nos cursos de licenciaturas são curriculares e critério de aprovação e obtenção de diploma, as atividades devem envolver os educandos no processo de ensino e aprendizagem. Logo, o seminário concebido como aprendizagem colaborativa torna-se primordial no processo de codificação do saber, pois é neste momento que os envolvidos apresentam na plataforma virtual de aprendizagem a vivência em campo de estágio e podem compartilhar experiências.

Inicialmente tínhamos um formato de seminário, onde os alunos participavam do fórum de discussões apresentando toda a vivência no campo de estágio. Era por meio desses registros e experiências apresentadas no fórum que os professores travavam as discussões e dialogavam entre os depoimentos e relatos apresentados. Este debate era gravado em formato de aula e disponibilizado aos acadêmicos no ambiente virtual de 
aprendizagem em forma de seminário.

Porém, como o seminário não era uma atividade avaliativa e a participação do acadêmico na aula não era critério de aprovação, a audiência variava em torno de $22,5 \%$ em 2016. Um percentual que, enquanto professores universitários, consideramos baixo dentro do perfil de qualidade que pretendemos atingir no processo de ensino e aprendizagem, cujo grande objetivo é codificar saberes distanciando-se da dicotomia presente entre a teoria e a prática conforme Barreiro e Gebran (2006) preconizam.

Felizmente em 2017 decidimos mudar a metodologia empregada. Desejávamos aumentar a audiência e acesso a aula de seminário e ao mesmo tempo manter os critérios avaliativos. Não queríamos ganhar a participação dos alunos ofertando notas ou benefícios, mas sim conscientizá-los de que esta atividade era importante para a formação profissional. Então, em meados do ano de 2017 passamos a utilizar o seminário com um novo formato, utilizando-se de recursos tecnológicos, mais especificamente fazendo uso do Skype durante as gravações.

Atualmente 17,6 milhões de brasileiros usam Skype, então não havia justificativas para continuarmos com o formato tradicional.

$\mathrm{Na}$ nova organização e estrutura do seminário participa uma equipe de docentes, discentes convidados e diversos alunos dos diferentes polos espalhados pelo Brasil, conectados através da ferramenta Skype. Assim, proporcionando mesas redondas, onde docentes e discentes debatem sobre assuntos diversos, entre eles, experiências vivenciadas no próprio estágio, contribuindo para a formação docente e acadêmica.

Com o uso do Skype foi possível uma maior interação entre os envolvidos. Nossos discentes passaram a olhar a atividade como suporte pedagógico e a audiência nos seminários passaram de 22,5 \% em 2016 para 61,5\% em 2017 (Figura 1). 


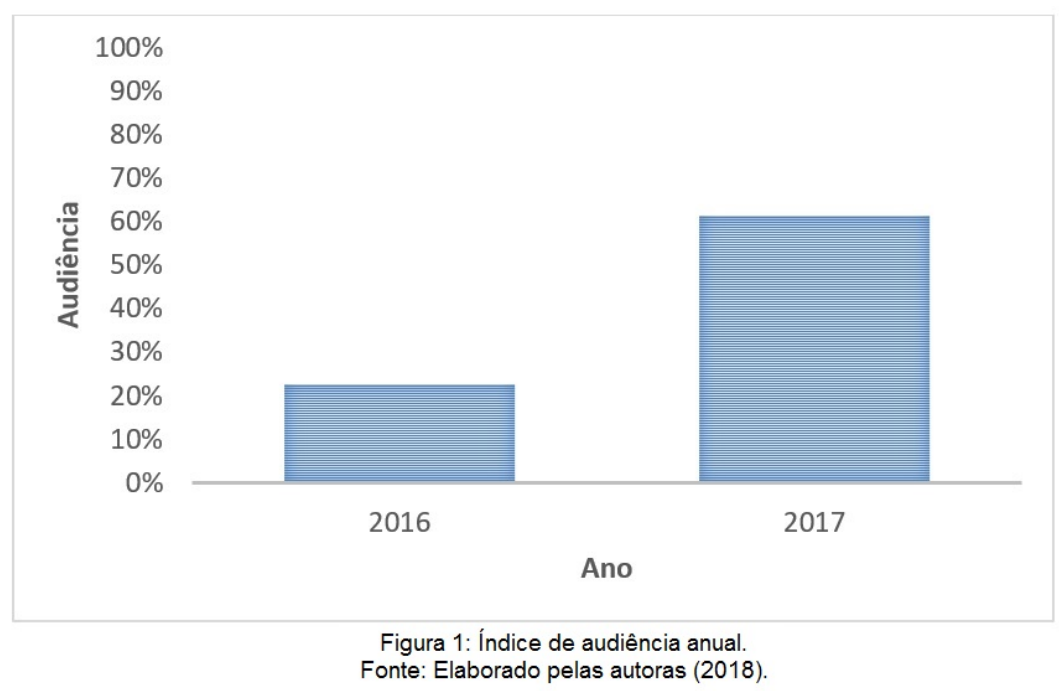

Uma mudança de metodologia que antes era pautada apenas no saber docente pronto e acabado renovou-se através da aprendizagem colaborativa, onde os discentes passaram a se envolver no processo de formação e mesmo aqueles que não estão diretamente envolvidos nas gravações dessas aulas, assistem ao seminário na plataforma virtual de aprendizagem e podem sentir-se envolvidos no processo de ensino e aprendizagem, pois se identificam nos depoimentos e discussões dos colegas, sempre respeitando as identidades regionais e suas deliberações educacionais.

Os cursos de licenciaturas em estudo apresentam-se estruturados em módulos, objetivando conferir melhor adequação aos sistemas gerenciais acadêmicos e, principalmente, agrupar conteúdos inter-relacionados de forma a garantir a qualidade do processo de ensino e aprendizagem.

Na Figura 2 apresenta-se um comparativo modular entre os anos de 2016 e 2017. Podese perceber que no módulo 51 (primeiro do ano letivo) passou de 16\% em 2016 para $66 \%$ em 2017, atingindo a maior audiência registrada nos bancos de dados. 


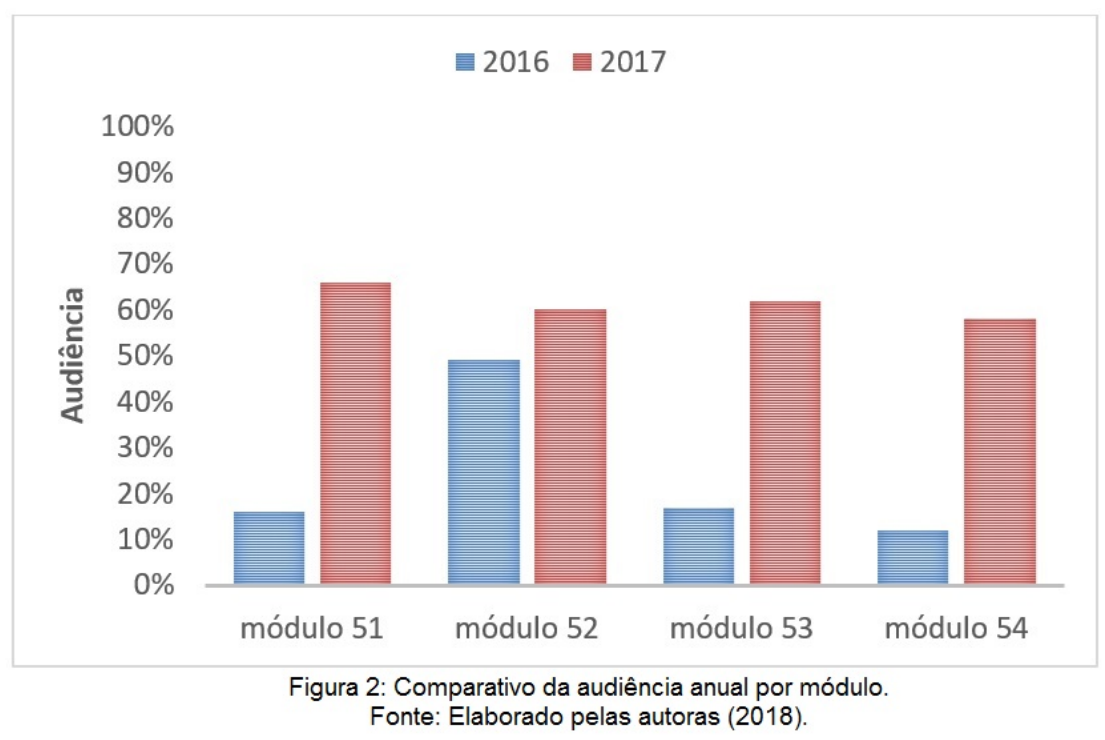

A elevação do índice (de 2016 a 2017) é observada em todos os módulos do ano letivo. No módulo 54, último do ano letivo há uma pequena queda, o que pode ser justificado pelo período em que o mesmo se realiza, uma vez que as aulas de seminário são disponibilizadas em meados de dezembro, período que se inicia as festividades natalinas e de final de ano.

\section{CONSIDERACÕES FINAIS}

A proposta de utilização do Skype como ferramenta de aprendizagem, nos proporcionou um suporte pedagógico dentro da disciplina de Estágio Supervisionado, possibilitando ampliar o potencial de aprendizagem através da participação colaborativa, apresentando caminhos para uma formação docente de qualidade, agregando novos olhares ao processo de ensino e aprendizagem e; proporcionando a troca de saberes entre docentes e discentes na modalidade a distância.

Com base nos resultados apresentados, tornou-se possível constatar que uma ferramenta comum, pode tornar-se fundamental para o processo de ensino e aprendizagem, firmando o compromisso enquanto instituição e educadores ao proporcionar um ensino de qualidade em diferentes ambientes de aprendizagem, possibilitando aos envolvidos buscar caminhos diferenciados com um único objetivo construir conhecimento colaborativo.

Os dados comprovam que os processos metodológicos necessitam de mudanças qualitativas, com atividades que envolvam os discentes no processo de aprendizagem e os direcionem com efetividade a uma formação sólida. Assim este artigo, buscou 
apresentar um panorama das possibilidades de inovação na metodologia, a fim de desenvolver a aprendizagem colaborativa dentro da educação a distância através do uso de ferramentas utilizadas no cotidiano trazendo-as para o ambiente virtual de aprendizagem.

\section{REFERÊNCIAS BBLIOGRÁFICAS}

BARREIRO, Iraíde Marques de Freitas; GEBRAN, Raimunda Abou. Prática de ensino e estágio supervisionado na formação de professores. São Paulo: Avercamp, 2006.

BRASIL. Parecer CNE/CP: № 02 de 01 de julho de 2015. Estabelece as Diretrizes Curriculares Nacionais para a Formação Inicial e Continuada dos Profissionais do Magistério da Educação Básica. Brasília, 2015.

C. A; SANTORO, Flávia Maria; BORGES, Marcos R. S.; SANTOS, Neide. Cooperação e aprendizagem on-line. Rio de Janeiro: DP\&A, 2003.

JANUARIO, Gilberto. O Estágio Supervisionado e suas contribuições para a prática pedagógica do Professor. In: Seminário de história e investigações de/em aulas de matemática, 2, 2008, Campinas. Anais: II SHIAM. Campinas: GdS/FE-Unicamp, 2008. v. único. p. 1-8.

PALLOF, Rena M.; PRATT, Keith. Estimulando a Aprendizagem Colaborativa. In: Construindo Comunidades de Aprendizagem no Ciberespaço: estratégias eficientes para salas de aula on-line. Porto Alegre: Artmed, 2002.

PICONEZ, Stela C. Berthola (coord.). A prática de ensino e o estágio supervisionado. Campinas, SP: Papirus, 2004 (Coleção Magistério: Formação e Trabalho Pedagógico).

PIMENTA, Selma Garrido; LIMA, Maria Socorro Lucena. Estágio e docência. São Paulo: Cortez, 2009. 